\section{Why Are Allergens Not Detected in the Bronchoalveolar Lavage Fluid of Patients Undergoing Fiberoptic Bronchoscopy? Possible Explanations}

Liccardi $\mathrm{G}^{1,2}$, Calzetta $\mathrm{L}^{3}$, Milanese $\mathrm{M}^{4}$, Bilò $\mathrm{MB}^{5}$, Rogliani $\mathrm{P}^{2,3}$ ${ }^{1}$ Department of Pulmonology, Haematology and Oncology. Division of Pulmonology and Allergy Unit. High Speciality "A.Cardarelli" Hospital, Naples, Italy

${ }^{2}$ Postgraduate School of Respiratory Medicine, Department of Experimental Medicine, University of Rome "Tor Vergata", Rome, Italy

${ }^{3}$ Department of Experimental Medicine, Unit of Respiratory Medicine, University of Rome "Tor Vergata", Rome, Italy

${ }^{4}$ Division of Pulmonology, S. Corona Hospital, Pietra Ligure, Italy ${ }^{5}$ Department of Internal Medicine, Allergy Unit University Hospital Ospedali Riuniti - Department of Clinical and Molecular Sciences, Polytechnic University of Marche, Ancona, Italy

J Investig Allergol Clin Immunol 2019; Vol. 29(6): 472-473 doi: 10.18176/jiaci.0429

Key words: Allergen. Allergic rhinitis. Allergic sensitization. Bronchial asthma. Bronchoalveolar lavage. Hypersensitivity. Pet allergy. Small airways.

Palabras clave: Alérgeno. Rinitis alérgica. Sensibilización alérgica. Asma bronquial. Lavado broncoalveolar. Hipersensibilidad. Alergia a animales domésticos. Vías aéreas pequeñas.

\section{To the Editor:}

We read with interest the excellent article from Rueda et al [1] showing that major allergens from various sources (mites, molds, and pollens) were not detected in bronchoalveolar lavage (BAL) fluid collected from patients undergoing fiberoptic bronchoscopy (FB) for a series of indications. The topic is relevant and worthy of study. However, we would like to underline limitations that can potentially influence the results and suggest further studies.

Firstly, the peak atmospheric presence of Alternaria and grass pollens throughout the world can fluctuate according to local conditions. In the Mediterranean area, clinically significant values are found in spring and summer $[2,3]$. During these critical periods, Alternaria can cause severeto-fatal asthma exacerbations [4], and asthma-related events induced by grass pollens may require visits to the emergency department [5]. In the case of Barcelona, the pollen calendar shows grass in the environment from the last days of April to the first days of July [6]. As FB was performed consecutively over 1 year, it would be useful to know its temporal distribution (eg, plotted on a graph) to assess whether this could have significantly affected the results for pollens and molds (grass and Alternaria), which have a very narrow window of detection. Secondly, when exploring a perennial allergen model, it would also be appropriate to perform enzymelinked immunosorbent assay with allergens of common pets (cats/dogs), in addition to house dust mites [7]. Clearly, pet allergens must also be considered a "true" perennial allergen in indoor environments, both in the presence and in the absence of the animals (direct/indirect exposure) [8-10]. Another important reason for choosing pet allergens is the characteristics of allergen-transporting particles. Several studies have demonstrated that about $25 \%$ of cat/dog allergens are carried by submicronic particles (less than 1-2 $\mu \mathrm{m}$ ), which easily become airborne under natural air ventilation. These particles are able to penetrate into the deep airways and induce persistent allergenic stimulation and prolonged small airway obstruction in previously sensitized individuals [11-13]. In fact, Zeidler et al [14] demonstrated that natural exposure to cat allergen (based on cat room challenge) results in significant small airway obstruction and hyperresponsiveness, which persists for at least 23 hours, as measured by pulmonary function testing and high-resolution computed tomography.

These data strongly suggest that the search for dust and pet allergens in BAL fluids throughout the year would be more likely to be successful because of their persistent presence in indoor environments, unlike Alternaria and grass pollens, whose presence outdoors is limited to a few months a year.

Finally, we suggest a possible explanation for the gap between the presence of Der $\mathrm{p} 1$ in BAL reported by Ferguson and Broide [15] and its absence in the study of Rueda et al [1]. In our opinion, healthy individuals and patients with other nonasthmatic chronic respiratory diseases, such as the vast majority of those described by Rueda et al [1], did not constitute an adequate model for the study of penetration of aeroallergens into the lower respiratory tract. The main difference between the 2 groups is the presence of nasal events (hypersecretion, congestion, mucosal hypertrophy, and even nasal/maxillary polyposis) and consequent upper airway obstruction in most asthmatics. In these common conditions, asthmatics breathe open-mouthed, thus short-circuiting the physiological nasal filter and enabling easier penetration of allergens and other environmental pollutants into the distal airways. It is well known that endotracheal intubation constitutes a relevant risk factor for bronchospasm in noncontrolled asthmatics undergoing diagnostic/therapeutic procedures [16,17]. Nevertheless, we believe that allergen penetration into distal airways should be assessed only in asthmatic patients after an optimal preprocedure evaluation $[16,17]$

In conclusion, it is likely that the absence of Der $p 1$, Alt a 1, and Phl p 5 in BAL fluids might depend on the choice of allergen (seasonal rather than perennial), period of the year in which BAL fluids were collected, and respiratory diseases requiring FB. Further studies should be planned as indicated above. 


\section{Acknowledgments}

We thank the veterinarian Dr. Giovanni Menna, who acted as pet consultant, and the biologists Drs. Giusy Sabatino and Mariagrazia Iengo for their kind assistance in the preparation of this manuscript.

\section{Funding}

The authors declare that no funding was received for the present study.

\section{Conflicts of Interest}

The authors declare that they have no conflicts of interest.

\section{References}

1. Rueda M, Lopez-Matas MA, Agusti C, Lucena C, Carnes J, Valero A. Allergens are not detected in the bronchoalveolar lavage fluid of patients undergoing fiberoptic bronchoscopy. J Investig Allergol Clin Immunol. 2019;29:148-50.

2. Filali Ben Sidel F, Bouziane $H$, Del Mar Trigo M, El Haskouri $F$, Bardei $F$, Redouane $A$, et al. Airborne fungal spores of Alternaria, meteorological parameters and predicting variables. Int J Biometeorol. 2015;59:339-46.

3. García-Mozo H. Poaceae pollen as the leading aeroallergen worldwide: A review. Allergy. 2017;72:1849-58.

4. O'Hollaren MT, Yunginger JW, Offord KP, Somers MJ, O'Connell EJ, Ballard DJ, et al. Exposure to an aeroallergen as a possible precipitating factor in respiratory arrest in young patients with asthma. N Engl J Med. 1991;324:359-63.

5. Hayden TJ, Muscatello DJ. Increased presentations to emergency departments for asthma associated with rye grass pollen season in inland NSW. N S W Public Health Bull. 2011;22:154-8.

6. Available at: https://lap.uab.cat/aerobiologia/general/pdf/ calendaris/cal_pol_barcelona_en.pdf

7. Miller JD. The Role of Dust Mites in Allergy. Clin Rev Allergy Immunol. 2018 Jun 23. doi: 10.1007/s12016-018-8693-0.

8. Liccardi G, Calzetta L, Baldi G, Berra A, Billeri L, Caminati $M$, et al. Allergic sensitization to common pets (cats/dogs) according to different possible modalities of exposure: an Italian Multicenter Study. Clin Mol Allergy. 2018 Feb 2;16:3. doi: 10.1186/s12948-018-0081-z. eCollection 2018.

9. Liccardi G, Salzillo A, Calzetta L, Piccolo A, Rogliani P. Assessment of pet exposure by questionnaires in epidemiological studies (but also in clinical practice!): Why the questions should be simplified? J Asthma. 2016;53:879-81.
10. Liccardi G, Triggiani M, Piccolo A, Salzillo A, Parente R, Manzi F, et al. Sensitization to Common and Uncommon Pets or Other Furry Animals: Which May Be Common Mechanisms? Transl Med UniSa. 2016;14:9-14.

11. Custovic A, Simpson A, Pahdi H, Green RM, Chapman MD, Woodcock A. Distribution, aerodynamic characteristics, and removal of the major cat allergen Fel $d 1$ in British homes. Thorax. 1998; 53:33-8.

12. Custovic A, Green $R$, Fletcher A, Smith A, Pickering $C A$, Chapman MD, et al. Aerodynamic properties of the major dog allergen Can $f$ 1: distribution in homes, concentration, and particle size of allergen in the air. Am J Respir Crit Care Med. 1997; 155:94-8.

13. Liccardi G, D'Amato G, Russo M, Canonica GW, D'Amato L, De Martino $M$, et al. Focus on cat allergen (Fel $d$ 1): immunological and aerodynamic characteristics, modality of airway sensitization and avoidance strategies. Int Arch Allergy Immunol. 2003;132:1-12.

14. Zeidler MR, Goldin JG, Kleerup EC, Kim HJ, Truong DA, Gjertson DW, et al. Small airways response to naturalistic cat allergen exposure in subjects with asthma. J Allergy Clin Immunol. 2006;118:1075-81.

15. Ferguson P, Broide DH. Environmental and bronchoalveolar lavage Dermatophagoides pteronyssinus antigen levels in atopic asthmatics. Am J Respir Crit Care Med. 1995;151:71-4.

16. Liccardi G, Salzillo A, Sofia M, D'Amato M, D'Amato G. Bronchial asthma. Curr Opin Anaesthesiol. 2012;25:30-7.

17. Liccardi G, Salzillo A, De Blasio F, D'Amato G. Control of asthma for reducing the risk of bronchospasm in asthmatics undergoing general anesthesia and/or intravascular administration of radiographic contrast media. Curr Med Res Opin. 2009;25:1621-30.

Manuscript received June 14, 2019; accepted for publication June 24, 2019.

\section{Gennaro Liccardi}

Department of Pulmonology, Haematology and Oncology, Division of Pulmonology and Allergy Unit.

High Speciality "A. Cardarelli" Hospital. Piazzetta Arenella $n^{\circ} 7,80128$ Naples, Italy

Postgraduate School of Respiratory Medicine. Department of Experimental Medicine, University of Rome

"Tor Vergata", Rome, Italy

E-mail: gennaro.liccardi@tin.it 